\title{
Effect of forming pressure on the reactivity and microstructure of zircon powder compacts
}

\author{
A. BONAMARTINI CORRADI, C. LEONELLI, T. MANFREDINI, C. SILIGARDI \\ Department of Chemistry, University of Modena, Via G. Campi 183, 41100 Modena, Italy
}

Zirconium is a commonly occurring element that is widely found (it ranks as the 20 th most abundant element in the Earth's crust, at 220 p.p.m.). Zircon $\left(\mathrm{ZrO}_{2} \cdot \mathrm{SiO}_{2}\right)$ is an abundant and inexpensive natural mineral and is mined in very large quantities, and it occurs throughout the world in mineral deposits. The most important deposits are found in Australia, South Africa, the USA, the former USSR and China [1]. It presents a very high chemical stability, i.e. high resistance to melt corrosion, as well as a high thermal stability (up to about $1670^{\circ} \mathrm{C}$ ) [12].

As zircons are natural raw materials, they contain impurities with a typical content of $1-2 \%$ (impurities can lower the temperature of decomposition of zircon, influence the mechanisms of chemical reaction of zircon, play an important part in the sintering of bodies, by producing liquid phases at the boundaries of the reaction grains, etc.) [3]. It appears that reaction sintering of a zircon-based mixture may lead to interesting microstructures. However, zircon is considered in the literature to be a not readily sinterable material [4]. Temperatures in the range $1600-1650{ }^{\circ} \mathrm{C}$ are required to produce reasonably dense bodies. Even milled material has over $14 \%$ porosity when sintered at $1580^{\circ} \mathrm{C}$ [5]. Clay is commonly added to commercial materials to act as a binder. This practice degrades the material by reducing its hot strength and rendering it susceptible to slag attack.

Zircon is known to dissociate at temperatures above about $1670^{\circ} \mathrm{C}$ [6] to form $\mathrm{ZrO}_{2}$ and $\mathrm{SiO}_{2}$ and to react with other oxides with $\mathrm{ZrO}_{2}$ as a reaction product [3]. Upon slow cooling a partial recombination of the zirconia and silica can occur. The zircon-zirconia system is well suited for the fabrication of composites because the two phases are compatible in all proportions at temperatures up to $1675^{\circ} \mathrm{C}$ [6]. In general, decomposed zircon powders are readily sinterable and can be used to fabricate relatively dense and strong materials.

In order to satisfy the requirements for the production of dense or high-porosity materials, it is necessary to understand the physico-chemical processes that occur during sintering. Therefore, the appropriate conditions for the sintering process must be known. An exact description of the sintering process is almost impossible because of the large number of influencing factors. Recent works $[7,8]$ have proved that slip casting is a powerful method to avoid agglomerates during consolidation and, consequently, to increase the final density and mechanical properties of the sintered bodies.
The objective of this letter is to present the preliminary results of a study on the effects of the forming pressure on the reactivity, sintering and microstructure of very fine natural zircon powder compacts. The effects of compaction pressure on the green densities and sintered densities are also discussed.

Zircopax (TAM Ceramics Inc., Bridge Station, Niagara Falls, New York, USA) natural zircon $\left(\mathrm{ZrSiO}_{4} 96 \mathrm{wt} \%, \mathrm{Al}_{2} \mathrm{O}_{3} 0.7 \mathrm{wt} \%, \mathrm{SiO}_{2} 2.2 \mathrm{wt} \%\right.$, $\mathrm{K}_{2} \mathrm{O}+\mathrm{Na}_{2} \mathrm{O} 0.7$ wt $\%$ and $\mathrm{TiO}_{2} 0.3$ wt $\%$ ) powders (average particle size $1.31 \mu \mathrm{m}$ ) were used in the study. Green compacts in the shape of bars were made by pressing (at 45, 90 and $180 \mathrm{MPa}$ ) weighed amounts of humidified $(5 \mathrm{wt} \%$ ) powders in a double-action die, giving specimens about $2.5 \mathrm{~mm} \times 8 \mathrm{~mm} \times 8 \mathrm{~mm}$. After drying, the dimensions of the compacts were measured to $0.01 \mathrm{~mm}$.

The unfired compacts were sintered in air up to $1500{ }^{\circ} \mathrm{C}$ and furnace-cooled. In situ dimensional changes were observed continuously with a conventional dilatometer (Netzsch model 402, Selb, Germany) at a constant heating rate of $10^{\circ} \mathrm{Cmin}^{-1}$. The microstructure of the sintered specimens was observed with a scanning electron microscope (PSEM 500, Philips, Eindoven, The Netherlands). The apparent densities and porosity of compacts were measured by the Archimedes method using distilled water. The linear shrinkage of the specimens was measured to $0.01 \mathrm{~mm}$.

Fig. 1 shows the dilatometric behaviour of dried green compacts as a function of the compaction pressure. In all samples shrinkage starting from about $1150-1170{ }^{\circ} \mathrm{C}$ was observed. As can be seen, the compaction pressure does not influence the

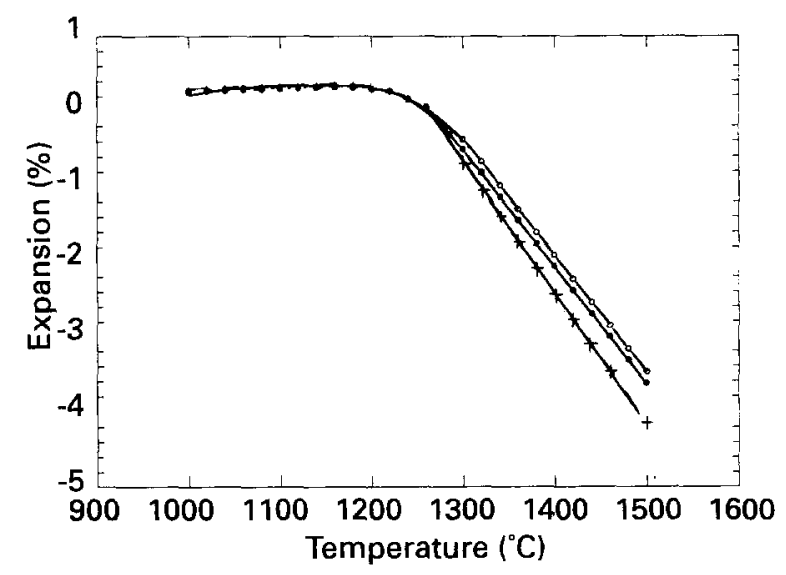

Figure 1 Dilatometric behaviour of dried green compacts. Compaction pressure (+) $45 \mathrm{MPa},(\bullet) 90 \mathrm{MPa}$ and $(\mathrm{O}) 180 \mathrm{MPa}$. 
sintering onset temperature, and the linear shrinkage measured at $1500^{\circ} \mathrm{C}$ decreases with increasing compaction pressure. This can be easily explained considering the variations in green density of zirconium specimens (Table I). In the same table the change in the density of fired samples as a function of the compaction pressure is given. The density values are consistent with the increase of compaction pressure; the changes in density depend directly on the change in the compaction pressure. These results are comparable with the literature $[2,4,5,7,8]$, but

TABLE I Sample density (mean of five specimens) as a function of compaction pressure (density of powder $4.45 \mathrm{~g} \mathrm{~cm}^{-3}$ )

\begin{tabular}{clllll}
\hline & \multicolumn{2}{l}{$\begin{array}{l}\text { Apparent density } \\
\left(\mathrm{g} \mathrm{cm}^{-3}\right)\end{array}$} & & \multicolumn{2}{l}{$\begin{array}{l}\text { Relative density } \\
(\%)\end{array}$} \\
\cline { 2 - 3 } \cline { 5 - 6 } $\begin{array}{l}\text { Pressure } \\
\text { (MPa) }\end{array}$ & Green & Sintered & & Green & Sintered \\
\hline 45 & 2.53 & 3.11 & & 55.5 & 70.1 \\
90 & 2.62 & 3.22 & & 57.5 & 72.3 \\
180 & 2.72 & 3.31 & & 59.6 & 74.3 \\
\hline
\end{tabular}
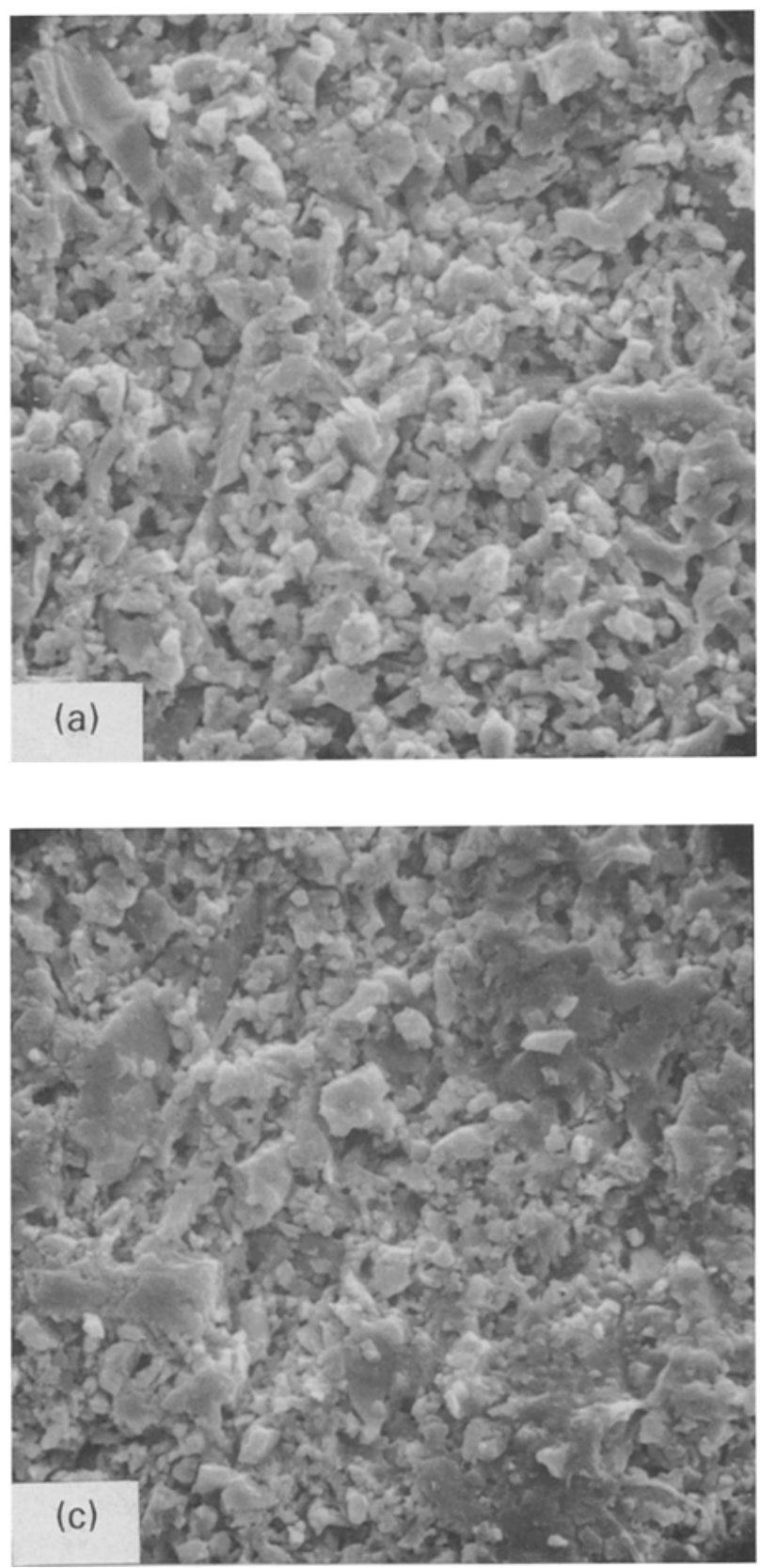

the porosity of samples obtained in the present work after sintering at $1500{ }^{\circ} \mathrm{C}(70.1,72.3$ and $74.3 \%)$ is lower than the corresponding data for samples obtained at higher temperature and sintered more (with 4 and $5 \mathrm{~h}$ soak at the sintering temperature) by Moreno [2] by slip casting (porosity $4 \%$ ) and by Garvie [4] starting from dissociated zircon (porosity $8 \%)$.

In Fig. 2 characteristic scanning electron micrographs of the polished surface of sintered specimens are shown. The surfaces of specimens were observed to be not filled by glassy phase, and the figure shows specimens to be very poorly sintered. The different microstructures and small differences in densification and especially in microstructure are imputable to the compaction pressure. This agrees with the bulk density of the fired specimens.

The relationship between the density and the compaction pressure governs the mechanism that occurs in the consolidation process. The investigation has demonstrated changing the compaction pressure in the range $45-180 \mathrm{MPa}$ does not influence the onset temperature of sintering of powdered zircon $\left(1150-1170{ }^{\circ} \mathrm{C}\right)$ but does influence the apparent density of the green compacts and consequently the porosity of the sintered specimens. Low relative density values were obtained in these sintering conditions.

Detailed microstructural investigations are in progress with zircons of different particle size in the presence of sintering-aid oxides in order to increase the sintering of powders at temperatures below $1500{ }^{\circ} \mathrm{C}$ and to improve the characteristics of the sintered compacts.

\section{Ackowledgements}

The authors are grateful to CNR and to MURST,

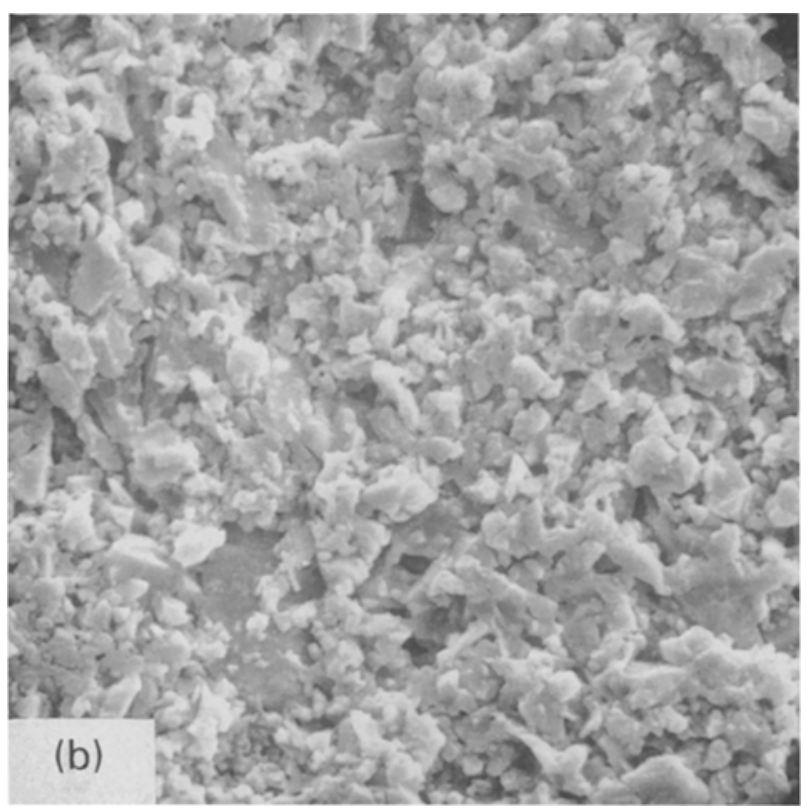

Figure 2 Scanning electron micrographs $(\times 2000)$ of the fractured and polished surface of sintered samples. Compaction pressure (a) $45 \mathrm{MPa}$, (b) $90 \mathrm{MPa}$ and (c) $180 \mathrm{MPa}$. 